\title{
A Study on Chinese-English Translation Standard of Landscape Public Signs Along the "Road of Tang Poetry" in Eastern Zhejiang Province*
}

\author{
Ning Zhao \\ Zhejiang Yuexiu University, China \\ Yong $\mathrm{Wu}$ \\ Zhejiang Yuexiu University, China
}

\begin{abstract}
Based on the development background of the "Road of Tang Poetry" in eastern Zhejiang, this paper discusses the influence of the non-standard Chinese-English translation of public signs along the "Road of Tang Poetry" on the development of the "Road of Tang Poetry," which to some extent hinders the acceptance and understanding of foreigners and affects the international dissemination of Chinese culture. Therefore, it is urgent to regulate the translation of public signs in scenic spots. This research studies the theory and practice of translating public signs from the perspective of translation norms discuss the problems existing in translating public signs in the vital scenic spots of "Road of Tang poetry" in eastern Zhejiang Province. This research also puts forward corresponding translation principles and strategies, hope that relevant developments can pay attention to and standardize the translation of public signs in scenic spots, to promote the promoting role of the translation of public signs in the construction of the "Road of Tang poetry" in eastern Zhejiang, and deepen the level of the foreign communication and exchanges.
\end{abstract}

Index Terms - landscape of the road of Tang poetry, Chinese-English translation standard public signs

\section{INTRODUCTION}

In 1991, Professor Zhu Yuebing, a famous scholar, first put forward the concept of "Road of Tang Poetry," pointing out the "Road of Tang Poetry in Eastern Zhejiang." The whole "Tang poetry road" refers to the ancient tourist scenery in ancient Shanzhong, where Tang poets traveled frequently and greatly influenced Tang poetry's development. It starts from Xixing of Qiantang River, passes through Xiaoshan to Jianhu River of Shaoxing, follows East Zhejiang Canal to Cao'er River, then goes along the river to Yanxi, passes through Tianmu Mountain in Xinchang, and finally arrives at Tiantai Mountain. It is about 200 kilometers in length. Among the more than 2,200 poets in the Tang poems, more than 300 famous poets have written more than 1,000 excellent works on this "Road of Tang poetry in eastern Zhejiang." In the past 30 years, more and more scholars and experts have gradually paid attention to the study of "Road of Tang poetry" in eastern Zhejiang province to explore its historical, economic, cultural, and other values. The governor of Zhejiang Province, Mr. Yuan, also pointed out in the government work report that the government should actively build a road for Tang poetry in eastern Zhejiang. "Building the Golden Tourism Belt of the Road of Tang Poetry" has also been the critical content of the "All-region Tourism Promotion Project" according to the Action Plan for the Construction of the Great Garden in Zhejiang Province in 2019. The "Road of Tang Poetry" program is listed as the first of the ten landmark projects in the construction of the Great Garden.

As Zhejiang's open strong province strategy continued to deepen, it attracted more foreign tourists, international students, and staff to get to work and travel. Hence, the demands for translation are increasing. However, inevitable translation often causes foreigners confused about aesthetic concepts and psychological tendencies. For instance, the poor quality of translation services, disordered market management, lack of corresponding standards, incomplete and uneven translation level, some fallacies or misunderstandings caused by cultural differences in the translation process. Although Standard for English Translation and Writing in the Field of Public Service were published in 2017, there are still some problems of promoting the implementation of the standard and how to promote and apply the national standard locally to achieve the standard of translation service. The standardized translation is the need to improve the quality of the city's external publicity and the opportunity for the country to enhance the level of civilization and the development of national soft power. The landscape translation along the "Road of Tang Poetry in Eastern Zhejiang" is an essential part of the construction of the international language environment of cities in Zhejiang Province and is also a critical transmission window to tell the "China story" well through the "Road of Tang Poetry."

\footnotetext{
* This study was funded by grants from the 2020 National College and University Student Innovation and Entrepreneurship Training Program Project (202012792001) and the project of undergraduate student innovation and entrepreneurship training of Zhejiang Yuexiu University "A Study of Bilingual Signs along the 'Road of Tang Poetry' from the Perspective of Translation Normative Theory” 
Western translation scholars have studied translation norms since the 1980s. With the rise of descriptive translatology, translation scholars began to investigate translation norms from social culture and ideology and describe them objectively. Toury (Newmark, 2001) is the first scholar to study norms from translation studies systematically. He pointed out firstly that "translation is determined by history, society, and culture; it is a behavior restricted by norms." According to his theory of translation norms, the translator's choice is the choice of translation norms. Norms are central in translation behavior and translation activities. Norms are becoming central in translation behavior in translation activities. Subsequently, Toury also clearly indicated that norms are reflected in specific acts (Harges, 2013). Translation norms are not necessarily translation strategies but lead to a strategy's choice or a reasonable explanation of a strategy. The restriction function of the specification to the selection simplifies the selection procedure to a certain extent. Toury constructs his theoretical framework of translation norms, which divides translation norms into preliminary norms, initial norms, and operational norms. Initial norms require translators to choose between "adequacy" translation and "acceptability" translation. According to Toury's theory, translation is the reappearance of the source text in another culture. The former tends to the source text and source text cultural norms, while the latter tends to target text or target text cultural norms as far as possible, and translators engage in translation activities between these two extremes (Song, 2007).

Later, Chesterman, Hermans, Nord, and others have carried out in-depth research on the nature and applicability of translation norms. Compared with Toury's definition of norms, Hermans stated that the purpose of studying translation norms is not only to analyze the equivalence between the source text and the target text. He also emphasized finding out how norms affect the translator's choice of the source text, the determination of translation strategies and methods, the acceptance of the target text in the purpose and culture, and people's understanding of the translation and the translated works in a specific situation or context, etc. Chesterman also deeply discussed some fundamental issues of translation norms, such as the source of norms, the influence of norms on specific translation activities, and the implied values behind norms. He divided translation norms into three categories: social norms, moral norms, and technical norms. In comparison, Nord's translation theory is relatively simple compared with the above three scholars' translation norms theory. This normative view is based on speech act theory and mainly examines the relationship between people in translation activities (Zhou, 2009).

On the other hand, tourism translation belongs to applied translation, but there is little research abroad. From the perspective of specific translation studies, international translation research fields mainly focus on explaining the importance of tourism translation from article subject matter and sociolinguistics. For instance, British scholar Sumberg (Dai et al., 2012) once emphasized that France as a trailblazer was elected as the most popular tourist destination for British tourists in history. He also provided much evidence to support the view that tourism translation has played a vital role in promoting tourism's rapid development in France. American scholars Dann (Li \&Huang, 2005) mentioned that tourism text has its characteristics and pointed out that the language of tourism text is more comprehensive than people once imagined. Through tourism translation, millions of potential tourists are induced to achieve tourism behaviors, and the attitude and behavior of tourists will also be affected by tourism translation (Li, 2016).

Compared with the study of translation norms abroad, China's research in this field is not systematic. Since the beginning of the 21 st century, the results of foreign research on translation norms have exerted a particular influence on translation studies in China (Xu, 2009). There have been several types of research on normative research. Some scholars have applied normative theory to specific translation practices in China, while others have studied the influence of specific translation norms on translation activities by combining the translator's subjectivity analysis (Wang \& Chen, 2004). However, these studies are far from sufficient to reconstruct the new translation norms in the development of Chinese translation to guide later generations' translation activities. Under the new historical conditions, it is necessary to sort out and absorb the results of western studies on translation norms, combining the analysis of social and cultural contexts in different historical periods and the description of linguistic features of specific translated texts, and construct a theory of translation norms on English-Chinese translation or Chinese-English translation (Huang, 2011).

Above all discussions, the main research questions of this study are as follows.

1.What are the main types of English-Chinese translation errors of public signs along the "Road of Tang Poetry" in eastern Zhejiang?

2. How to effectively standardize the English-Chinese translation of public signs along the "Road of Tang Poetry" in eastern Zhejiang?

\section{Methodology}

This part is an empirical study on the bilingual translation of public signs along the "Road of Tang Poetry in Eastern Zhejiang." By studying the problems existing in English-Chinese bilingual translation, some errors of public signs of English-Chinese translation types are confirmed. The errors are mainly considered from the following aspects. Such as wrong translation, mistranslation, leaking translation, surplus translation, spelling errors, grammatical errors, a misnomer, pragmatic failures, semantic fuzziness, different versions, Chinglish, Chinese pinyin misuse, incorrect punctuation, abuse of uppercase and lowercase, proper nouns are not standard, stiff mechanical machine translation, translation does not conform to the English expression habit, improper handling of cultural information, improper handling of taboo words and so on. Through field investigation, this paper collects, statistics, and analyzes the 
landscape translation materials along the "Road of Tang Poetry in Eastern Zhejiang," summarizes the typical characteristics of non-standard translation, and seeks solutions to various errors.

\section{RESULTS}

1. The landscape of the public language translation error categories includes: wrong translation, mistranslation, surplus translation, spelling errors, grammatical errors, a misnomer, pragmatic failures, semantic fuzziness, different versions, Chinglish, Chinese pinyin misuse, incorrect punctuation, abuse of lowercase and uppercase, printing and typesetting layout is not standard, proper nouns are not standard, stiff mechanical machine translation, improper handling of taboo words, concept expression uniform, not in conformity with the English expression habit and so on. The following aspects are included: language errors, pragmatic failure, and the translator's ability a

\section{Language errors}

Language errors mainly include orthographic errors, grammatical errors, and lexical errors. Orthographic errors mean errors in spelling, capitalization, punctuation, and so on. Lexical errors refer to improper use of words, including errors in meaning, collocation, ambiguity, speech, color, and cultural connotation. Grammatical errors are mainly manifested in single and plural numbers, part of speech, word order, person, tense, voice, articles. With the introduction and promotion of the Code for English Translation and Writing in the Field of Public Service, the translation of public signs in urban public places has been paid attention to and standardized, the translation quality of public signs has been improved to a certain extent, and the problem of language errors has been reduced. However, in some places, the quality of the translation of public signs is still worrying, especially some apparent mistakes that do not conform to the language norms and grammatical rules, which hinder the city's appearance. For example, in an office area of exciting spots, the translation of “办公区域, 请勿进来” is “OFFICE AREA, PLEASE DON'T COMING," where there is an obvious grammatical error here, and visitors will have very negative visual perceptions of this scenic spot. Setting another example, W.C. in the abbreviation for the expression of the word "则所" is used in many scenic spots in China. This translation is a very vulgar way of expression, and it will give a person with crude, not very clean feeling. Britain, the United States, and other English-speaking countries have many using this abbreviation, such as Toilet, Bathroom, Restroom or Washroom are more elegant words, which can be translated as "公共卫生间."

\section{Pragmatic failure}

Pragmatic errors include redundant and rigid translation, distortion of communicative information, Chinglish, cultural misunderstanding, inappropriate occasions, wrong questions, ambiguous semantics, poor formula effect, and so on (Wang, 2011). This kind of problem mainly reflects the translator's subjective initiative and intercultural communication ability. For instance, the sign "须佩戴口罩进入" is always read at the entrance of the exciting place. Most of the staff of interesting spots translated it as"Must wear a mask when entering." This sentence has been translated directly according to the translator's literal meaning, and it seems that the language is correct and the meaning is well conveyed. However, the tone is stiff and stern, which makes people uncomfortable. We can translate it into "A mask is required when entering," It is better because the tone is moderate, neither too blunt nor too mild to be coercive. Such a situation requires the translator to give full play to his subjective consciousness, understand the starting point and environment of the text, adopt appropriate translation methods, conform to English expression habits, and achieve public signs' display effect.

\section{The translator's ability}

Some scholars have mentioned that the lack of translation standards is the environmental reason for the poor quality of translating public signs in scenic spots (Ding, 2006). However, the translator is the main body of translation, and the professional quality of public sign translators in scenic tourist spots is the decisive factor to determine the quality of translation. Researchers have found that translators' professional qualities include Chinese-English language foundation, cross-cultural awareness, and ability to transfer between Chinese and Western cultures, and translation attitude, and so on. However, the relevant government management agencies lack attention or paid no attention to the translation of public signs in scenic spots. From the translator's perspective, when translating public signs, the translator acts as the person responsible for language and cultural translation and should be a talented person with professional skills. However, at the present stage, there are diverse translation talents, which leads to the various quality of translated works to a certain extent. As for the translation profession, most people in the current society still cannot truly understand from an academic perspective that translation is a highly professional profession and the misunderstanding that people can do a translation if they know a foreign language is still common. Translators should have solid language ability and good intercultural communication ability and be able to fully understand the responsibility consciousness of translators in translation work, namely, the importance of translation work, the sense of mission of language and culture communication, the overall awareness of foreign cultural display, and the conscious awareness of traditional culture transmission (Huang, 2011).

\section{DISCUSSION}

So far, the principles and strategies of public sign translation have been studied from various perspectives, including pragmatic perspective, cross-cultural perspective, communicative function perspective of the text, skopos theology of 
research, aesthetic perspective, and so on. The translation of public signs is an applied text translation, which should be standardized. Besides, the study should be conducted from the perspective of cross-cultural communication. It should take into account both the current text information and the target language audience, the use environment of the translation of public signs, and fully grasp the restrictive effects of context, culture, communicative role, and other factors on successful translation of public signs. This research will discuss the translation strategies of public signs from the following three aspects.

\section{Follow the standard principle of public sign translation}

The translation of public signs is mainly classified as fixed signs. According to the Standard for English Translation and Writing of Public Service Areas, it is divided into nine sectors: transportation, tourism, culture, entertainment, sports, education, medical and health care, postal services and telecommunications, catering and accommodation, and business and finance. The Standard for English Translation and Writing of Public Service Areas provides the "official interpretation" published by the national standard, involving common nouns and short sentences in the public domain. It also provides a model and standard for Chinese and English signs in urban public places and a large extent unifying and standardizing the previous multiple translations, translation inconsistency, wrong translation, omission of translation, and other problems. Based on these rules, hence, before the translation of public signs, translators need to study the Standard for English Translation and Writing of Public Service Areas carefully to ensure that their translation conforms to the translation and writing standards. For the part not involved in the Standard for English Translation and Writing of Public Service Areas, the translator should also be flexible, adapt to the situation, and not copy blindly.

\section{Fully study the text to reflect the communicative function of the text}

Public signs are a kind of applied text. When translating public signs, translators need to take complete account of the types of public language texts and consider translation strategies from language characteristics, environment, communicative purpose, and the acceptance of the target language audience. For instance, the public sign "老弱病残孕 专座" on a subway is translated as "The seats are reserved for the aged, children, the sick and disabled, pregnant women." This statement is too lengthy, and the translator did not consider the characteristics of the text. The subway's public signs should be concise and comprehensive, and the information should be clearly expressed. Also, the translation is thoroughly copied from Chinese and defines the group taking the seat, which exposes the group's privacy and does not conform to the expression habits of the target language audience. This kind of error does not study the characteristics of the text and ignores the audience's cultural characteristics and psychological factors, which will lead to the dissatisfaction of the audience. The more appropriate translation should be "Courtesy Seats," which is simple and straightforward to achieve public signs' presentation effect in the subway. It also fully considers the cultural habits of the audience and has high acceptability.

\section{Familiar with the cultural differences between Chinese and western culture, in line with the cultural habits} of the target language

The translation is a cross-linguistic and intercultural communicative activity. The translation of public signs often involves the collision of differences between two cultures. The cultural standpoint of the translator and the cultural standpoint of the target language audience are different from each other in politics, economy, region, traditional culture, customs, and so on. The cultural difference will cause the deviation of understanding and bring difficulty to translation. Therefore, translators of public signs need to have the ability to understand and communicate the cultural differences between China and the West to achieve high-quality translation. In the context of public health emergencies in 2020 , many public signs with such themes have been translated and written. For instance, at the entrance of the scenic spot, there is a notice saying “请出示绿码”, which corresponds to "Please present green code" in English. The translator has translated word for word, but the confusion caused by the "绿码" to the target language audience has not been considered. The green code is a new development in this year's environment, and its precise concept should be"健康 码," indicating whether the holder is currently from an area at high risk of an epidemic or a reflection of his or her health condition. Furthermore, "健康码" this measure is only implemented in local countries and regions and is not a well-known thing. Therefore, to reduce cultural cognition confusion, the translation should be accurate, and the more appropriate translation is "Health code is required." In this way, the audience can easily understand that “绿码" is a two-dimensional code related to physical health, which plays a more influential role in communication.

\section{Translation methods and Countermeasures}

The purpose of translation determines the selection of translation strategies and the adjustment of translation principles. The translation of public signs in scenic spots is based on "convey in words" and centered on "express or convey one's ideas." In translation practice, "at the macro level, we develop quality translation outlines, carefully select the source text and adjust the chapter structure appropriately; at the micro-level, we pay attention to the use of translation techniques such as adding, deleting, clarifying the meaning, combining and reorganizing information and rewriting analogies. " In the paper, scholars mentioned that some suggested translation methods and Strategies of public signs in scenic spots include: transliteration, literal translation, omission, adaptation, amplification, loan-translation, parody translation, parsimony, merging, abbreviation, analogy, adding notes, graphic translation, communicative translation, semantic translation, naturalization, and foreignizing translation, etc. They emphasized that translators of public signs in scenic spots should adopt various translation strategies, deeply study the translation norms of public 
signs in scenic spots, and seriously grasp the text acceptance expectations of foreign tourists. Maximize the communicative function of translating public signs in scenic spots and provide accurate and complete English information of public signs for scenic spots. For example, the representative figure of Buddhist culture, "大慈大悲的观 世音菩萨," can adopt the translation strategy of Sanskrit plus Chinese pinyin plus English notes. The translation is Avalokite Avalokite Bodhisattva-Guan Shi Yin. (Buddism Bodhisattva of Great Mercy) . For example, some scenic spots with rivers and lakes will have signs to remind visitors that "水深危险, 注意安全" or "水况复杂, 请勿嬉水" and so on. We can adopt the principle of simplified translation for similar translations, and the translation is "Danger! Deep Water! ". This expression aligns with international public signs' general expression habits, with concise semantics and precise information.

\section{CONCLUSION}

This study takes the "Tang Poetry Road of Eastern Zhejiang," a hot spot in the economic zone of Zhejiang Province, as an entry point and takes into account the general trend of "opening up and strengthening the province" and "going global" of Chinese culture. There is a need to examine the norms of translation of popular attractions and their cultural transmission impact. Through the study of the standardization of English-Chinese translations of landscapes along the "Road of Tang Poetry in Eastern Zhejiang," it is helpful to understand the reasonable behavior and problems of bilingual sign language translations of landscapes along the "Road of Tang Poetry in Eastern Zhejiang," to understand further the translation process and its dissemination in the target language culture, and to explore the process of landscape translation. The study will also help understand the translation process and its dissemination in the target language culture, and explore the mode of translation and acceptance assessment of the landscape sign language, to spread Chinese culture better overseas.

\section{REFERENCES}

[1] Dai, Z.X., \& Lu, H. F. (2012). A Study on the Chinese-English Translation of Public Notices - Taking London, the Host City of the 2012 Olympic Games, as an Example--London, the host city of the 2012 Olympic Games, is an example. China Translation, 6, 38-42.

[2] Ding, H. Q. (2006). Striving to Improve City Public Notices and Progressively Establishing Reference Translations. China Translation, 6, 42-46.

[3] Harges, S. (2013) The International Progress and Trends of Ecological Translation. Shanghai Translation, 4, 1-4.

[4] Huang, Y. Y. (2011). Chinese translation with Chinese characteristics and the challenges it faces and suggestions for countermeasures. Chinese Translation, 6, 56-61.

[5] Huang, Z. L. (2009). Adaptation and Choice: An Exploration of Yan Fu's Translation Thought. Shanghai Translation, 4, 7-10.

[6] Li, Y. S., \& Huang, Z. L. (2005). A new theoretical construction-Reading Hu Geng Shen's Theory of Translation Adaptation. Foreign Language Teaching, 6, 95-96.

[7] Liu, L. F. (2011). Progress and prospect of research on Chinese public language. Chinese Foreign Languages, 11, 53-58.

[8] Newmark, P. (2001). A Textbook of Translation. Shanghai: Shanghai Foreign Language Education Press, 2001:39.

[9] Song, Z.P. (2007). The Theory of Translation Adaptation: A Work of Simplicity and Innovation. Foreign Language Research, 5 , 105-106.

[10] Sun, Y. C. (2011). Zhang Guruo and "Adaptation" and "Choice." Shanghai Translation. 4, 1-6.

[11] Wang, H. (2011). Discerning the core concept of ecological translation. Shanghai Translation, 4, 10-11.

[12] Wang, Y. Q., \& Chen, X. R. (2004). English translation errors of urban sign language and their examples. Chinese Translation, 25(2), 81-82.

[13] Xu, J.G. (2009). The Name and Reality of Foreign Propaganda Translation - A Review of Research after the 1990s. Journal of Ocean University of China (Social Science Edition), (2), 93-96.

[14] Zhou, Z. H. (2009). Research on Translation of Public Notices: A Theoretical Review and Reflection. Journal of Sichuan Education College, 11, 87-89.

Ning Zhao, a student of the English faculty, Zhejiang Yuexiu University. Her research interests include the English translation and English education.

Yong Wu, Ph.D., Associate professor, the deputy dean of English faculty, Zhejiang Yuexiu University. She specializes in translation, language education, Psycholinguistics and so on. 